\title{
Secondary cardiovascular prevention in clinical practice: what do we need today?
}

\author{
Gian Francesco Mureddu1,2 \\ ${ }^{1}$ Cardiology and Cardiovascular Rehabilitation Unit, Cardiovascular Department, S. Giovanni-Addolorata Hospital, \\ Rome; ${ }^{2}$ Italian Association of Clinical Preventive Cardiology and Rehabilitation, Italy
}

\begin{abstract}
In the last decades, the post-hospital mortality from coronary artery disease (CAD) has significantly increased. This new trend in the epidemiology of CAD has been largely attributed to the improvement of survival from acute coronary syndromes that generated increasing incidence of population at high risk of recurrences and rehospitalization for major adverse cardiovascular events (MACE) and heart failure (HF). Thus, much longer after the acute event than we had thought, we have now been facing with higher complexity of "chronic" CAD phenotypes which deserve high clinical attention and more and more intricate pharmacological management. Although the guidelines recommend implementing secondary prevention programs through cardiac rehabilitation (CR) facilities in order to achieve a better outcome, i.e. decreased morbidity, re-hospitalization and increased adherence to evidence-based interventions, the referral rate to CR is paradoxically scarce. The Italian Association of Clinical Preventive Cardiology and Rehabilitation (AICPR) has been launching a survey involving the Network of Italian CR centers, which will make possible to observe trends, implement guidelines recommendations and then verify the effectiveness of the interventions and outcomes in post-acute and chronic CAD.
\end{abstract}

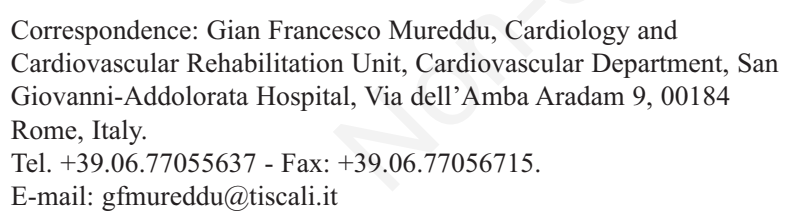

Conflict of interest: The author declares no conflict of interest.

Key words: Cardiac rehabilitation; preventive cardiology; long-term cardiovascular risk.

Received for publication: 28 August 2019.

Accepted for publication: 4 September 2019.

${ }^{\circ}$ Copyright: the Author(s), 2019

Licensee PAGEPress, Italy

Monaldi Archives for Chest Disease 2019; 89:1160

doi: 10.4081/monaldi.2019.1160

This article is distributed under the terms of the Creative Commons Attribution Noncommercial License (by-nc 4.0) which permits any noncommercial use, distribution, and reproduction in any medium, provided the original author(s) and source are credited.
In last ten years significant changes in the clinical epidemiology of acute coronary syndromes (ACS) have taken place. Despite the progressive reduction of in-hospital mortality, paradoxically, the post-hospital mortality has significantly increased [1-4]. This new trend in the epidemiology of coronary artery disease (CAD) has been largely attributed to the implementation of treatments of the acute phase of myocardial infarction (MI). As a consequence, the rising number of survivors has progressively increased the population at high risk of recurrences (major adverse cardiovascular events, MACE). This new scenario we are facing with, that was once called "stable" ischemic heart disease, is no longer to be considered as such. Both heart failure (HF) and the residual high atherothrombotic risk (HTR) [1,5] have been identified as the major independent predictors of recurrent MACEs. HTR can be detected both by clinical factors, such as diabetes mellitus, renal failure, peripheral artery disease, a history of angina or previous acute myocardial infarction (AMI), and by anatomical/surgical factors as the presence of multivessel disease, especially if treated with incomplete revascularization, or no revascularized at all. Both observation from registries [4,6] and epidemiological studies [1] show that patients with HTR may present with MACEs even far from the index event. In an Italian National retrospective cohort study from the administrative database of the National Health Institute that recruited 186.646 patients admitted for a MI from 2009 to 2010 in all the Italian hospitals, the risk of MACE remained high over 5 years after a first MI in patients with HTR. High residual risk had been defined, as commonly in most current studies, by at least one of the following: previous MI, vascular disease, type 2 diabetes mellitus or renal failure $(\mathrm{GFR}<60$ $\mathrm{ml} / \mathrm{min} / 1.73 \mathrm{~m}^{2}$ ) [7]. Intervention studies as the PEGASUS-TIMI 54 (Prevention of Cardiovascular Events in Patients with Prior Heart Attack Using Ticagrelor Compared to Placebo on a Background of Aspirin-Thrombolysis in Myocardial Infarction) [8,9] and the Dual Antiplatelet Therapy Study [10] have confirmed observational and epidemiological data. Prolonged dual antiplatelet therapy (DAPT) for up to three years yielded a prognostic benefit in selected patients at very high risk of ischemic recurrences. The IMPROVE-IT (Improved Reduction of Outcomes: Vytorin Efficacy International Trial) and nowadays the FOURIER [11] and ODYSSEY outcomes [12] have reinforced the notion that lowering the LDL-cholesterol level leads to a reduction in CV events continous, linear without any apparent threshold, emphasizing the need for long-term intensive secondary prevention in subgroups of patients with high residual atherothrombotic risk. Finally, in the recent COMPASS trial (Cardiovascular Outcomes for People Using Anticoagulation Strategies) [13], combination of aspirin and rivaroxaban at "vascular" doses has shown to be effective in improving survival even after 7-10 years after a first cardiovascular (CV) event in patients with coronary or 
peripheral vascular disease, indicating a further long-term potential therapeutic strategy and, in fact, offering a second chance even when the $\mathrm{CV}$ prevention facilities are scarce and continuity of care has been lacking [14]. Despite this large body of evidence, however, the adherence to pharmacological therapies after an acute event is far from being maintained over time. The main European survey (EUROASPIRE) on the effectiveness of a secondary prevention intervention [15] demonstrated that risk factors (RFs) control is far from be optimal. A central point in the success of secondary prevention programs is the referral to cardiac rehabilitation (CR) programs [16].

Meta-analysis of randomized trials and Cochrane showed decreases recurrent MI and morbidity rates either inpatients presenting with coronary heart disease [17] or HF [18]. CR participation is associated with a $20 \%$ to $30 \%$ reduction in hospital readmission during the year after a cardiac event [19-21]. Much of this effect is due to the increase in adherence to evidence-based therapy [22].

In the paper by Faggiano et al. recently published in the Monaldi Archives for Chest Disese [23], the authors aimed at evaluating the achievement of risk factors' control and appropriate drug prescription/adherence in patients attending secondary prevention/CR ambulatory visit after index $\mathrm{CV}$ event in a time period ranging 1 to 5 year. Eight hundred patients at a high risk, aged $69 \pm 10.9$ years were recruited. All patients were highly treated with evidence-based drugs. Patients that have participated to $\mathrm{CR}$ after a cardiovascular event showed best achievement in blood pressure and LDL-cholesterol targets. The goal of LDL-c $<70 \mathrm{mg} / \mathrm{dl}$ was achieved in about $70 \%$ of patients. Thus, implementing secondary prevention guidelines into the 'real world' clinical practice in "late" interval from 1 to 5 years after a cardiovascular event is feasible.

Hence, what should we have to do? Addressing appropriate care in the according to the individual patient's level of risk is the answer. The scientific community will have to verify not only the appropriateness of care and the adherence to the guidelines in secondary prevention centers, but also to monitor the referral rate to $\mathrm{CR}$ facilities form acute care centers. Participation in CR programs for patients hospitalized with CAD of HF in recommended by European guidelines in class I, level of evidence A [24]. The Survey On risk FactOrs and CardiovascuLar secondary prEventIon and drug strategieS in Italy (SOFOCLES)", is the answer by which the AICPR (Italian Association of Clinical Preventive Cardiology and Rehabilitation) intend to address these new needs in CV prevention. The survey will highlight the state of the art of diagnostic-therapeutic pathways of post-acute and chronic ischemic heart disease in Italy, will investigate the correct selection of high-risk patients and the appropriateness of pharmacological prescriptions in these subgroups. Furthermore it will investigate on the causes of non-optimal adherence to drug therapy in order to identify corrective measures in the management of care in CAD.

In conclusion, much more longer after the acute event than we had thought, we have to face with higher complexity of "chronic" CAD phenotypes (for the rising incidence of elderly population presenting with multiple comorbidities and multiple vessels disease), that deserve high clinical attention and more complex pharmacological management (prolonged DAPT; association between antiplatelet agents and anticoagulants at full or "vascular" doses; multiple association of ipolipidemic drugs); this can make difficult to evaluate the risk / benefit ratio and cost-effectiveness of care. A network of cardiovascular secondary prevention /cardiac rehabilitation centers will make possible to observe trends, implement the recommendations of the guidelines and then verify the effectiveness of the interventions.

This is the only way to check the appropriateness of our work and at the same time a great challenge of the future of preventive cardiology that we do not want to lose.

\section{References}

1. Greco C, Rosato S, D'Errigo P, et al. Trends in mortality and heart failure after acute myocardial infarction in Italy from 2001 to 2011. Int J Cardiol 2015;184:115-21.

2. Jernberg T, Hasvold P, Henriksson M, et al. Cardiovascular risk in post-myocardial infarction patients: nationwide real world data demonstrate the importance of a long-term perspective. Eur Heart J 2015;36:1163-70.

3. Krumholz HM, Wang Y, Chen J, et al. Reduction in acute myocardial infarction mortality in the United States: risk-standardized mortality rates from 1995-2006. J Am Med Assoc 2009;302:767-73.

4. Rosamond WD, Chambless LE, Heiss G, et al. Twenty-twoyear trends in incidence of myocardial infarction, coronary heart disease mortality, and case fatality in 4 US communities, 1987-2008. Circulation 2012;125:1848-857.

5. Kaul P, Ezekowitz JA, Armstrong PW, et al. Incidence of heart failure and mortality after acute coronary syndromes. Am Heart J 2013;165:379-385.e2.

6. Steg PG, Bhatt DL, Wilson PW, et al. One-year cardiovascular event rates in outpatients with atherothrombosis. JAMA 2007;297:1197-206.

7. Mureddu GF, D'Errigo P, Rosato S, et al. The hazard of major adverse cardiac events in high thrombotic risk patients is stable until 5 years after an acute myocardial infarction. Eur Heart J 2017;39;(s1):565 (P2487).

8. Bonaca MP, Bhatt DL, Cohen M, et al. Long-term use of ticagrelor in patients with prior myocardial infarction. N Engl J Med 2015;372:1791-800.

9. Bonaca MP, Storey RF, Theroux P, et al. Efficacy and safety of ticagrelor over time in patients with prior MI in PEGASUSTIMI 54. J Am Coll Cardiol 2017;70:1368-75.

10. Mauri L, Kereiakes DJ, Yeh RW, et al. Twelve or 30 months of dual antiplatelet therapy after drug eluting stents. N Engl J Med 2014;371:2155-66.

11. Sabatine MS, Giugliano RP, Keech AC, et al. Evolocumab and clinical outcomes in patients with cardiovascular disease. $\mathrm{N}$ Engl J Med 2017;376:18.

12. [Clinical Trial]. ODYSSEY outcomes: Evaluation of cardiovascular outcomes after an acute coronary syndrome during treatment with alirocumab trial. ClinicalTrials.gov identifier: NCT01663402.

13. Eikelboom JW, Connolly SJ, Bosch J, et al. Cardiovascular outcomes for people using anticoagulation strategies. N Engl J Med 2017;377:1319-30.

14. Gulizia MM, Colivicchi F, Abrignani MG, et al. Consensus Document ANMCO/ANCE/ARCA/GICR-IACPR/GISE/ SICOA: Long-term antiplatelet therapy in patients with coronary artery disease. Eur Heart J Suppl 2018;20(Suppl F):F1-F74.

15. Kotseva K, Wood D, De Backer G, et al. EUROASPIRE III: a survey on the lifestyle, risk factors and use of cardioprotective drug therapies in coronary patients from 22 European countries. Eur J Cardiovasc Prev Rehabil 2009;16:121-37.

16. Thomas RJ, Balady G, Banka G, et al. 2018 ACC/AHA clinical performance and quality measures for cardiac rehabilitation: A report of the American College of Cardiology/American Heart 
Association Task Force on Performance Measures. Circ Cardiovasc Qual Outcomes 2018;11:e00037.

17. Anderson L, Thompson DR, Oldridge N, et al. Exercise-based cardiac rehabilitation for coronary heart disease. Cochrane Database Syst Rev 2016; CD001800. doi: 10.1002/14651858. CD001800.pub3

18. Anderson L, Taylor RS. Cardiac rehabilitation for people with heart disease: an overview of Cochrane systematic reviews. Cochrane Database Syst Rev 2014; CD011273. doi: 10.1002/ 14651858.CD011273.pub2.

19. Giannuzzi P, Temporelli PL, Marchioli R, et al. Global secondary prevention strategies to limit event recurrence after myocardial infarction: results of the GOSPEL study, a multicenter, randomized controlled trial from the Italian Cardiac Rehabilitation Network. Arch Intern Med 2008;168:2194-204.

20. Doimo S, Fabris E, Piepoli M, et al. Impact of ambulatory cardiac rehabilitation on cardiovascular outcomes: a long-term follow-up study. Eur Heart J 2019 21;40:678-85. doi: 10.1093/ eurheartj/ehy417

21. Scalvini S, Grossetti F, Paganoni AM, et al. Impact of in-hospital cardiac rehabilitation on mortality and readmissions in heart failure: A population study in Lombardy, Italy, from 2005 to 2012. Eur J Prev Cardiol 2019;26:808-17.

22. Griffo R, Ambrosetti M, Tramarin R, et al. Effective secondary prevention through cardiac rehabilitation after coronary revascularization and predictors of poor adherence to lifestyle modification and medication. Results of the ICAROS Survey. Int J Cardiol 2013;167:1390-5.

23. Faggiano P, Fattirolli F, Frisinghelli A, et al. Secondary prevention advices after cardiovascular index event: from drug prescription to risk factors control in real world practice. Monaldi Arch Chest Dis 2019;89:1040. doi: 10.4081/monaldi. 2019.1040

24. Piepoli MF, Hoes AW, Agewall S, et al. 2016 European Guidelines on cardiovascular disease prevention in clinical practice: The Sixth Joint Task Force of the European Society of Cardiology and Other Societies on Cardiovascular Disease Prevention in Clinical Practice (constituted by representatives of 10 societies and by invited experts). Developed with the special contribution of the European Association for Cardiovascular Prevention \& Rehabilitation (EACPR). Eur Heart J 2016;37:2315-81. 
